\title{
A New Approach for Teaching Power Electronics Converter Experiments
}

\author{
Jacinto M. Jiménez-Martínez, Fulgencio Soto, Esther de Jódar, José A. Villarejo, and
} Joaquín Roca-Dorda, Member, IEEE

\begin{abstract}
This paper presents a new methodological approach to teaching power electronics converter experiments. This approach is based on a reconfigurable hardware-software platform for use in converter experiments in a basic power electronics course. This course is an optional subject, and, therefore, the experiments need to motivate the students. The platform is controlled by software (made in a LabVIEW environment) run on a PC. The student can control the fundamental parameters of the selected converter topology through the user interface and, with a little work, can compare the results with a real circuit. An example of use of the methodology in an inverter experiment is included.
\end{abstract}

Index Terms-Education, LabVIEW, power electronics, students' experiments.

\section{INTRODUCTION}

$\mathbf{P}$ OWER electronics is an important area within electrical engineering, for a number of reasons, which includes advances in semiconductor technology and new applications in microelectronics and industrial power electronic equipment, such as variable-speed motor drivers, uninterruptible power supplies, robotics, electric cars, and others [1].

Experience shows that power electronics as a subject is not readily assimilated by students because of the different areas involved. According to [2], laboratory experiments can help students assimilate the theoretical concepts of very complex subjects and make a first contact with the instrumentation and equipment students will work with in the future. Nevertheless, laboratory experiments, though ideally the best strategy, present problems of time, money, and safety. Therefore, the methodology used for teaching a power electronics laboratory is very important. Many references are in the literature related to methodology for laboratory experiments in power electronics and other similar areas [3], [4]. Most of the references include instructional software for controlling equipment and simulating some circuits [5], [6], such as MATLAB or LabVIEW, which are widely used in universities all over the world.

Simulation exercises can be very useful to beginner students in power electronics [7] and can help advanced students to prepare for further work at the laboratory. In addition, simulation can be helpful in reducing the need for repair of instruments and materials as a result of mistakes or accidents.

This paper presents a new methodological approach to teaching about power electronics converters in the laboratory.
The approach is based on a reconfigurable hardware-software (HW/SW) platform. This platform is controlled by software (made in the LabVIEW environment) run on a PC. The user can control the fundamental parameters of the selected converter topology through the user interface and, with a little work, can compare the results with a real circuit. The platform is an ideal complement for theoretical study. Experience has shown that the new equipment helps minimize the complexity and the time taken by experiments, provides an extra benefit for the students, and assures better overall use of laboratory sessions.

Section II if this paper presents the theoretical and practical contents of a basic power electronics converter course in which the system is used, establishes the pedagogical objectives for the laboratory, and expresses ways to attain these objectives. Section III details the laboratory equipment and the platform. Section IV presents a case study based on the methodology described in this paper. The results achieved with the use of the system in teaching a course of power electronics are described in Section V. Finally, the conclusion (Section VI) summarizes the benefits of this work and outlines future plans.

\section{Education Program in Power Electronics}

The theoretical concepts of the basic course proposed in this paper is outlined in Table I. These concepts are very similar to the power electronics curriculum proposed in [8].

The laboratory experiments (Table I) are intended to achieve the following goals [2]:

1) to reinforce and support lecture-based courses in power electronics;

2) to provide hands-on experience in practical power electronics applications;

3) to expose important measurement techniques and safety concerns in power electronics work;

4) to introduce the state-of-the-art simulation tools as employed extensively by industry.

In this basic course, the converter experiments are oriented to show clearly how these topologies work; complex control systems should therefore be avoided since these systems demand a higher level of comprehension and entail greater complexity in experiments. Suggested experiments have a first step based on simulation; it will help students to gain a better understanding of the circuit. Then, students are prompted to implement the circuit with a little extra work. In the platform, control of the electronic devices involved is automatic so that the experiment is less confusing for students.

The students carry out all the experiments following a laboratory handout. This handout was drafted on the basis of the 
TABLE I

OUtLine for Basic UndergraduATE COURSE IN POWER ElECTRONICS

\begin{tabular}{|c|c|}
\hline Theory & Experiments \\
\hline 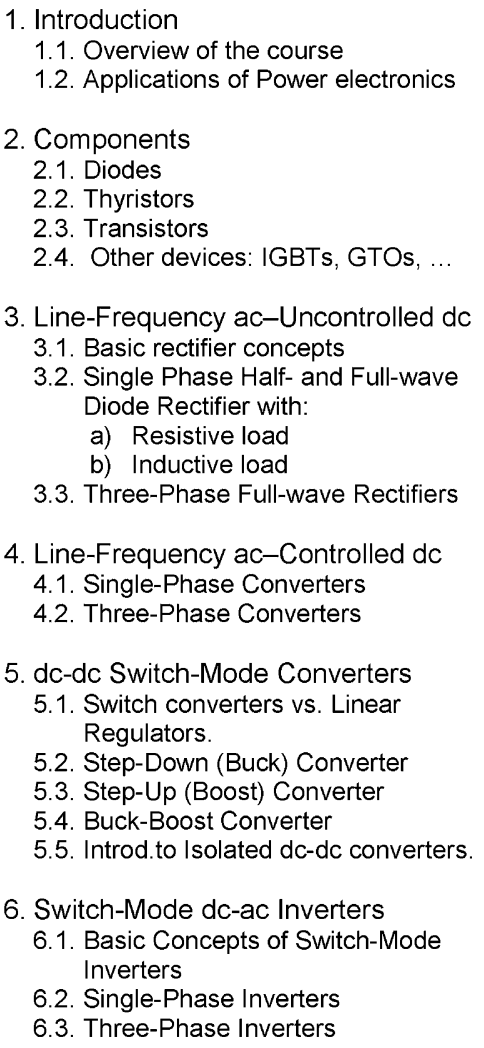 & $\begin{array}{l}\text { 1. The Power Electronics Lab } \\
\text { Instruments } \\
\text { 2. Safety in Power Electronics } \\
\text { 3. Computer simulation } \\
\text { 4. AC-to-DC conversion: Single- } \\
\text { Phase uncontrolled circuits } \\
\text { 5. AC-to-DC conversion: Three- } \\
\text { Phase uncontrolled circuits } \\
\text { 6. AC-to-DC conversion: Single- } \\
\text { Phase controlled circuits } \\
\text { 7. AC-to-DC conversion: Three- } \\
\text { Phase controlled circuits } \\
\text { 8. DC-to-DC switch mode } \\
\text { converters, Buck converter } \\
\text { 9. DC-to-DC switching mode } \\
\text { converters (DC motor drive } \\
\text { app.) } \\
\text { 10. DC-to-AC voltage: non- } \\
\text { modulated inverter } \\
\text { 11. DC-to-AC voltage: Single-Phase } \\
\text { PWM modulated inverter } \\
\text { 12. DC-to-AC voltage: Three-Phase } \\
\text { PWM modulated inverter } \\
\text { 13. Design and implementation of a } \\
\text { simple converter }\end{array}$ \\
\hline
\end{tabular}

objectives stated above with a number of rules based on experience. Clearly, a need is present to seek a middle ground between the number of concepts and tasks and the complexity level of the experiment.

Generally, every experiment includes a brief theoretical refresher on the concepts involved in the experiment, a schematic, a detailed list of the elements involved, blank tables for results, and some final questions that students have to answer.

At the beginning of the laboratory session, the teacher gives a brief explanation, presenting an overview of the experiment and the relation with the theory. The first session is the best time to discuss safety issues and how to avoid improper use of the equipment. The teacher should check the circuit before it is powered up. There is a laboratory session discussing safety in the laboratory because of the hazards inherent in power electronics circuits.

\section{LABORATORY FACILITIES}

The laboratory consists of eight workstations, each occupied by two people. Table II gives a detailed description of the material present in the laboratory. Special care has been taken to select equipment elements that meet safety standards and are easy to assemble and reconfigure.

Most of the experiments have been conducted using two power converter systems: the Power Electronics Teaching System (PETS) and the Multifunctional Thyristor Converter
TABLE II

LABORATORY EQUIPMENT

\begin{tabular}{|c|c|}
\hline Device & Unt. \\
\hline $\begin{array}{l}31 \text {-phase transformers. Different plugs for the secondary } \\
\text { winding. }\end{array}$ & 8 \\
\hline Inductive loads $(30 \mathrm{mH}, 75 \mathrm{mH}, 125 \mathrm{mH}, 256 \mathrm{mH}) . \quad \operatorname{Imax}=2 \mathrm{~A}$ & 8 \\
\hline Capacitor, $3.3 \mu \mathrm{F}, 450 \mathrm{~V}$ & 8 \\
\hline Variable resistor up to $100 \mathrm{ohms}$ and $1000 \mathrm{~W}$ & 8 \\
\hline SEMIKRON power electronics teaching system & 8 \\
\hline SEMIKRON multifunctional thyristor converter system & 8 \\
\hline Independent excited DC motor 400W, 220V & 4 \\
\hline Squirrel cage induction motor $736 \mathrm{~W}, 380 \mathrm{~V}$ & 4 \\
\hline Digital oscilloscope TDS210 & 8 \\
\hline Differential probe. $20 \mathrm{MHz}$ and $1200 \mathrm{~V}$ isolating voltage. & 8 \\
\hline Current probe. $150 \mathrm{KHz}$ and $100 \mathrm{~A}$ maximum current. & 8 \\
\hline Tachometer & 4 \\
\hline Reconfigurable platform & 8 \\
\hline Variable power supply $32 \mathrm{~V}, 1 \mathrm{~A}$ & 8 \\
\hline Function generator & 8 \\
\hline Personal computers & 8 \\
\hline
\end{tabular}

System (MTCS) from Semikron [9]. These power converter systems contain a three-phase diode rectifier, a three-phase thyristor converter, a capacitor bank, three half-bridges made of two isolated gate bipolar transistors (IGBTs), a brake chopper module, and drivers for triggering purposes. Moreover, the drivers monitor for undervoltage power supply, protect against short-circuits, and isolate the power system from the electronic control system. A picture and a scheme of PETS is shown in 

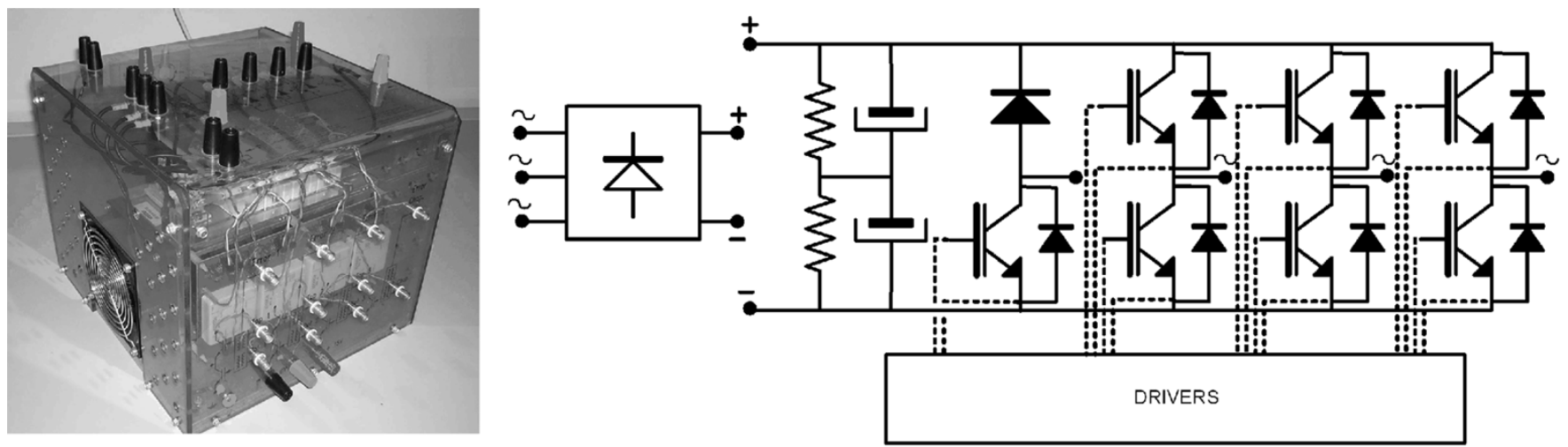

Fig. 1. PETS picture and schematic.

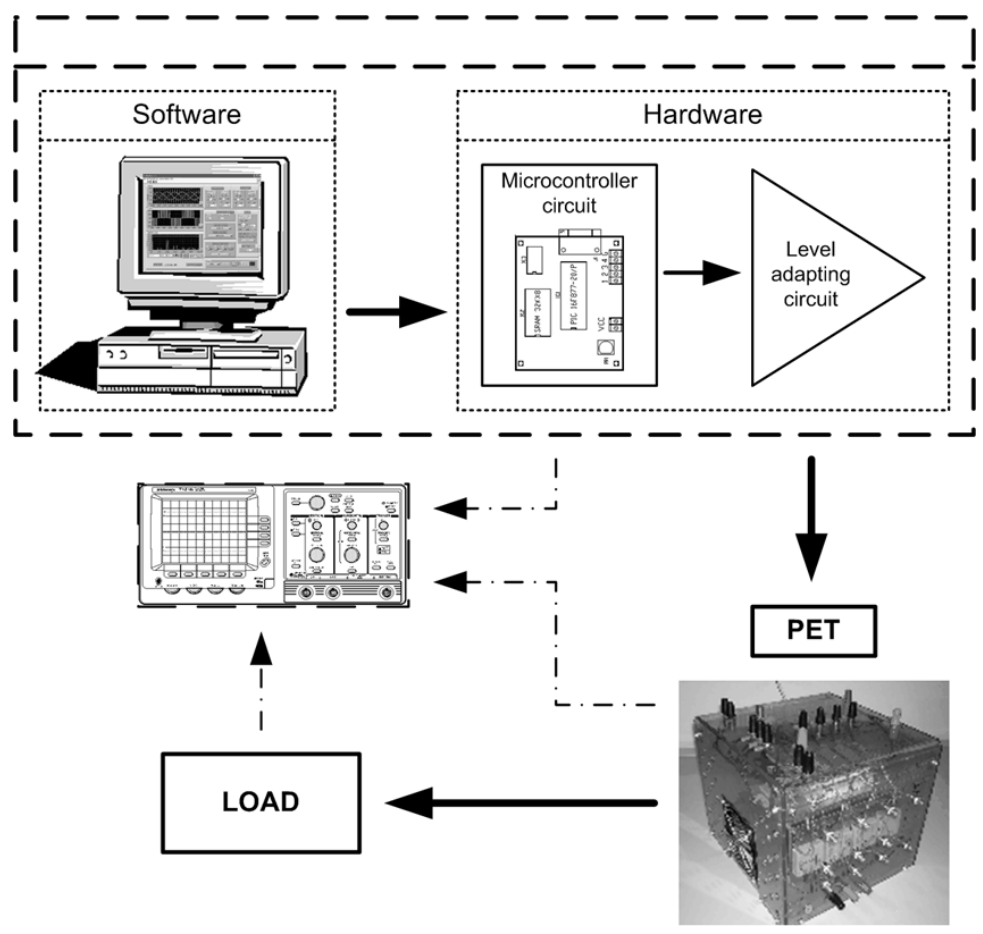

Fig. 2. Instrumentation for an experiment.

Fig. 1. These converters are industrial models to which a polymethylmethacrylate (PMMA) case has been added to prevent accidental contact. An additional protection is provided by using isolation transformers, fuses, and thermal and differential interrupts at the first stage of the circuit.

The reconfigurable platform is controlled by a PC. The PC is also used for other tasks, including circuit simulation with Pspice Lite, control of measurement instruments via communication protocols such as GPIB or RS232, registration and saving of measurements obtained with the equipment, and Internet navigation.

The reconfigurable platform has two different blocks: first, a software block that includes a user interface developed in the LabVIEW graphic environment, and second, a hardware block, consisting of a microcontroller for serial communications with the $\mathrm{PC}$ and a trigger and signal conditioning circuit for current buffering and adapting of voltage levels for converter power drivers. Fig. 2 shows the diagram of an experiment in which can be seen the PETS equipment. The LabVIEW environment has been chosen for the software block because it combines the advantages of graphical programming and high-quality user interface tools. A program made in LabVIEW is called a virtual instrument (VI) and is divided into a front panel, which is the user interface, and a block diagram, which is the program that controls the front panel.

The user interface is designed to provide simple interaction between student and software. Different converter topologies can be chosen from controlled rectifiers to modulated inverters. When a topology is selected, the front panel for this topology appears. An example of a front panel is shown in Fig. 3. Several control boxes are available for entering values of the main parameters, graphic displays to visualize the trigger signals, and selected voltage and current waveforms. A small area of the user interface is reserved for communication with the hardware block.

Through this zone, the user can transfer the trigger data to the microcontroller by RS232. The communication protocol is serial and includes a cyclic redundancy code to avoid transmit- 


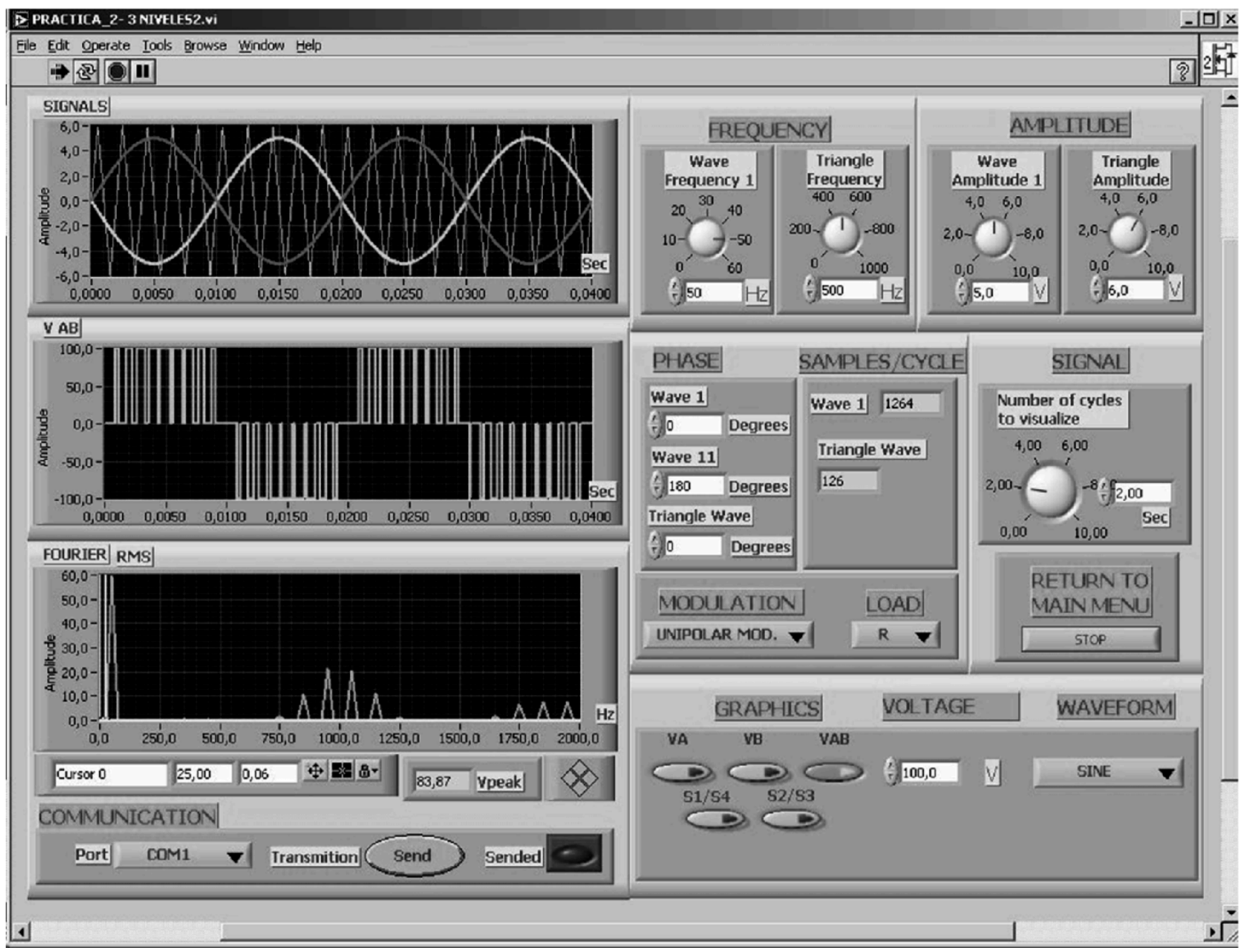

Fig. 3. Sample of the front panel for an inverter experiment.

ting or receiving errors in the signals involved. The PC transmits only one signal period to the microcontroller and repeats this single cycle as long as it is powered. The signal-conditioning circuit acts as a voltage-level interface between microcontroller and converter drivers and includes a switch allowing to inhibit the trigger signal manually.

Fig. 4 shows the program structure related to the front panel of Fig. 3. The front-panel input data (voltage and frequency) are used to calculate and generate the more important signals related to the converter. In addition to these signals, the program derives the output voltage Fourier spectrum, which will show the harmonic influence in each topology. The sample number by cycle and the sampling frequency (fixed value determined by the hardware) will be needed to plot the waveform. The above signals are displayed and optionally can be transmitted to the microcontroller.

\section{CASE STUdy: INVERTERS}

The following gives some details of the design and implementation of an experiment, to provide a clear idea of the possibilities. For the sake of brevity, the experiment with a full-bridge inverter (single phase) with unipolar modulation has been selected. The other experiments are conducted in a similar way.
The handout that students should follow during an experiment includes a brief summary of basic theory and formulas that can be used for modulated inverters. At the beginning, students are reminded of the theoretical concepts involved and make some calculations related to the triggering signals and voltage and load current.

Basically, for unipolar modulation, trigger signals are obtained by comparing a switching-frequency triangular waveform $\left(V_{\text {tri }}, f_{\text {tri }}\right)$ with two senoidal control signals $\left(V_{c 1}, f_{c 1}\right)\left(V_{c 2}, f_{c 2}\right)$. The logical signals for switch control $\left(T_{A+}, T_{A-}, T_{B+} T_{B-}\right)$ are given by the following:

$$
\begin{array}{ll}
\text { If } V_{c 1}>V_{\mathrm{tri}}, & \text { then } T_{A+}: \mathrm{ON} \\
\text { If } V_{c 1}<V_{\mathrm{tri}}, & \text { then } T_{A-}: \mathrm{ON} \\
\text { If } V_{c 2}>V_{\mathrm{tri}}, & \text { then } T_{B+}: \mathrm{ON} \\
\text { If } V_{c 2}<V_{\mathrm{tri}}, & \text { then } T_{B-}: \mathrm{ON} .
\end{array}
$$

The frequency modulation ratio $\left(m_{f}\right)$ and the amplitude modulation ratio $\left(m_{a}\right)$ are defined as

$$
m_{f}=\frac{f_{\mathrm{tri}}}{f_{c}} \quad \text { and } \quad m_{a}=\frac{V_{c}}{V_{\mathrm{tri}}} .
$$




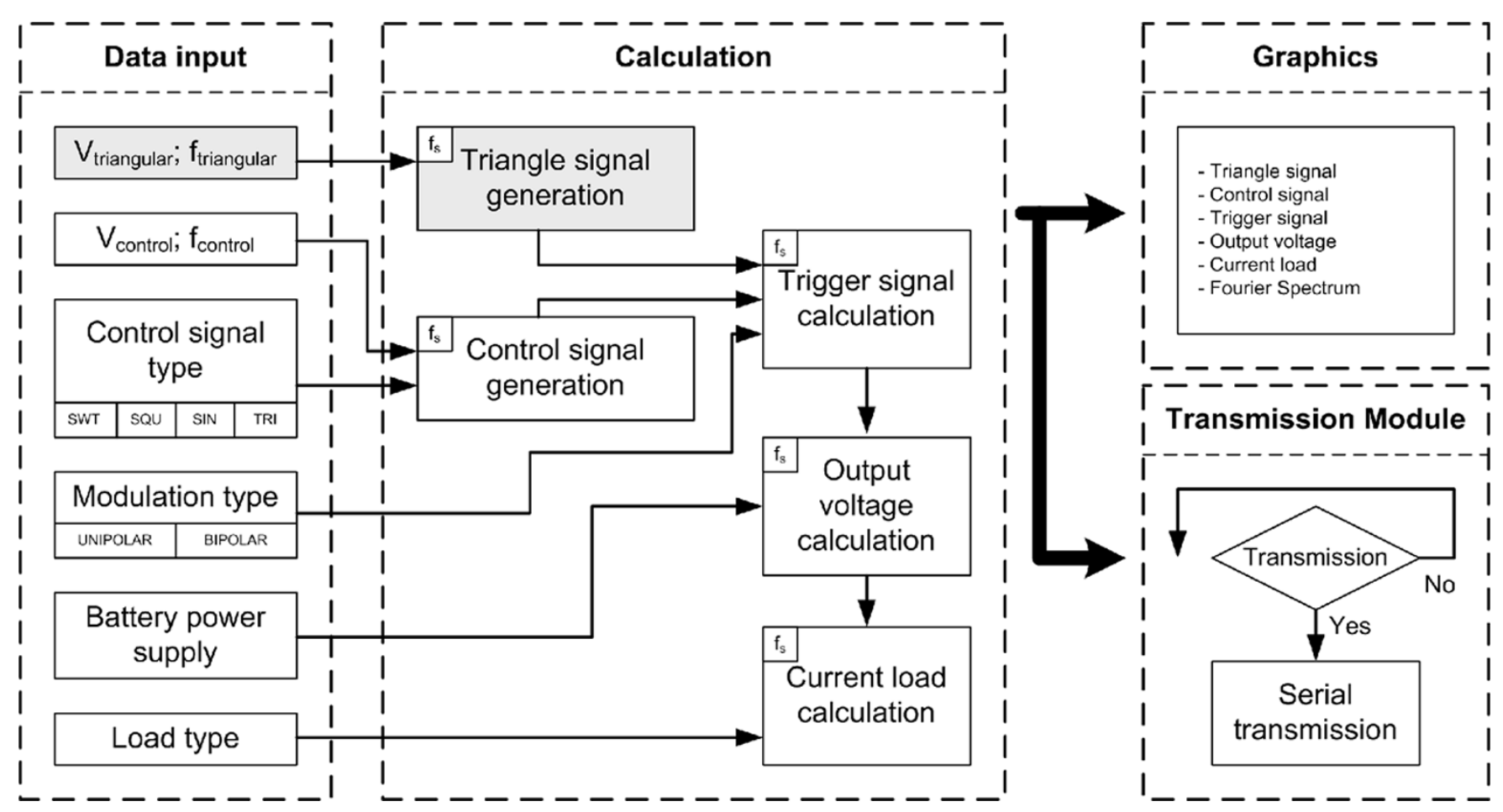

Fig. 4. Flow Diagram for the front panel of Fig. 3.

TABLE III

HANDOUT TABLE

\begin{tabular}{|c|c|}
\hline Input data & Result \\
\hline $\begin{array}{l}\text { Topology: Single-Phase PWM } \\
\text { modulated inverter } \\
\text { Modulation type: unipolar }\end{array}$ & $m_{f}=\frac{f_{t r i}}{f_{c}}=10$ \\
\hline $\begin{aligned} \text { Control signal: } & \\
& -\quad V_{c 1}=5 \mathrm{~V} \\
& -\quad V_{c 2}=5 \mathrm{~V} \\
& -\quad f_{c}=50 \mathrm{~Hz}\end{aligned}$ & \multirow[t]{2}{*}{$m_{a}=\frac{V_{c}}{V_{t r i}}=0.5$} \\
\hline Phase angle $(\varphi): 90^{\circ}$ & \\
\hline $\begin{aligned} \text { Modulation signal: } & \\
- & \text { triangular } \\
- & V_{t r}=10 \mathrm{~V} \\
- & t_{t r i}=500 \mathrm{~Hz}\end{aligned}$ & $V_{O 1}=V_{D} \cdot m_{a} \cdot \sin \frac{\varphi}{2}=35.35 \mathrm{~V}$ \\
\hline
\end{tabular}

At this step, students must calculate the fundamental-frequency component in the load from the dc battery voltage, the control signal amplitudes, and their frequencies and phase. Depending on the load type (selected by the teacher), students must derive an expression for the current and values for $m_{f}$ and $m_{a}$. These calculations must be written down on the handout, and the results entered in a table (Table III).

Subsequently, the students use the simulation included in the reconfigurable platform. Four inverter assemblies can be selected: half-bridge (single phase), full-bridge (single phase) with bipolar modulation, full-bridge inverter (single phase) with unipolar modulation, and three-phase. When the third assembly is selected, the front panel shown in Fig. 3 is displayed. In this screen, students have to enter the input data: modulation and reference signal type, switching-frequency waveforms and reference signals voltage and frequency, input voltage amplitude, load type, and number of cycles to visualize. Then, the waveform of switching-frequency signal and reference signals, the transistor trigger signals, the output signal and its Fourier spectrum, and the load current will be displayed. In this way, students can obtain a simulation of a real assembly and can verify the actual results according to their prior calculations based on theoretical knowledge. If the values are not correct, students are forced to review either the prior calculations or the input data. The platform allows this feedback, which is very useful for students because it helps them to consolidate theoretical concepts.

Next, the students must conduct the experiment with the laboratory elements according to the block diagram. The connection details are included in the handout. Once the teacher has reviewed the assembly, the power is implemented. The trigger data are sent from the PC to the microcontroller, and students can see the trigger signals, load voltage, current, etc., on the oscilloscope. For the data in Table III, the oscilloscope will show the waveforms (Fig. 5) which are very similar to the ones in the front panel of Fig. 3.

\section{ExPERIENCE ObTAined From This Method}

After the basic experiment is explained in the previous section of this paper, students have reinforced their theoretical knowledge of modulated inverters with unipolar control. Students are satisfied with the use of the platform as presented here, since it is a very useful aid in carrying out this experiment and the other converter experiments. The degree of satisfaction is supported by the increased number of students registering for the course since the platform was first used in experiments three years ago (Fig. 6). The basic course presented here is conceived as an optional subject for second-year students of industrial engineering, a general degree course; therefore, the subject needs to be attractive to students. 


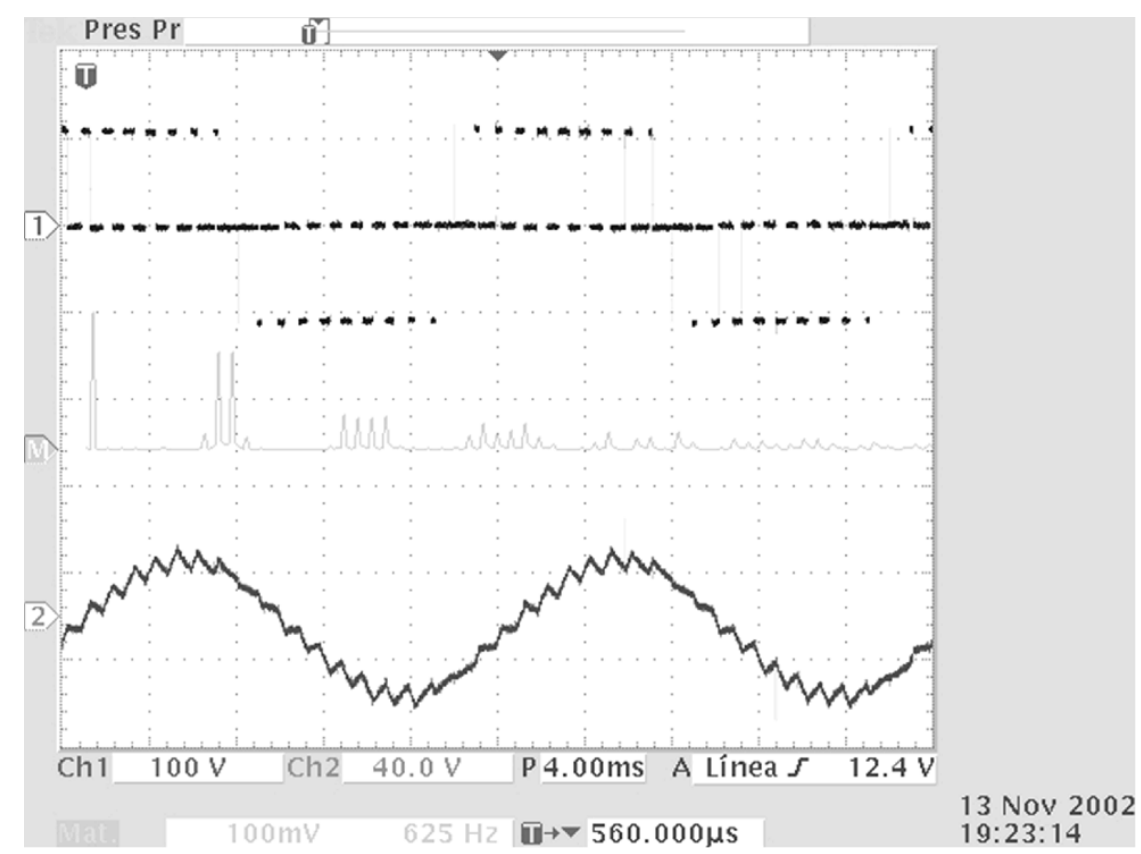

Fig. 5. Results obtained from the inverter experiment in laboratory.

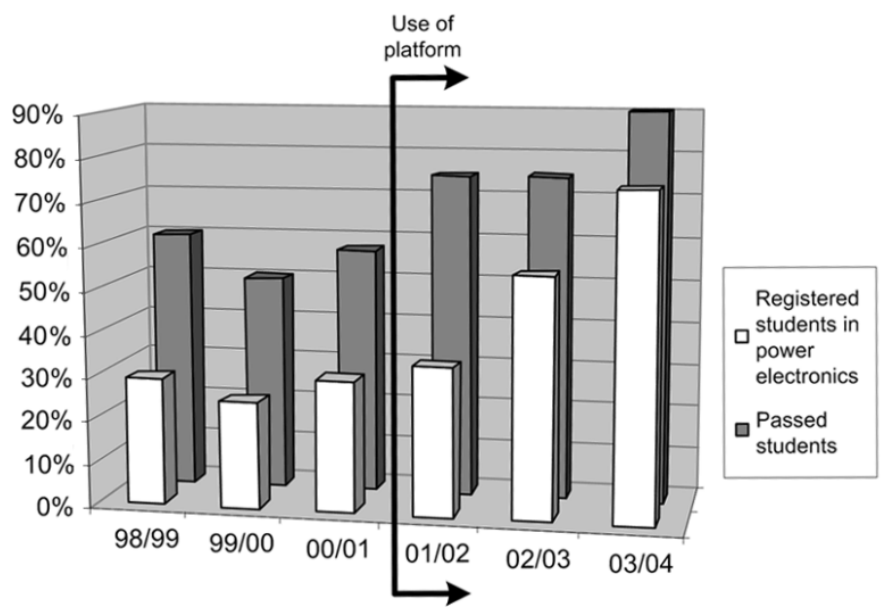

Fig. 6. Percentage of second-year industrial engineering students registered in power electronics and percentage of students passing this subject in the last six years.

Before the platform was used to conduct the converter experiments, a specific trigger generation board was used for each assembly, and circuit simulation was executed with Pspice. The platform combines simulation and control; in addition, it makes the simulation faster and simpler for the student. Another advantage is that now the total number of boards is smaller so that less material and less maintenance time are required.

The simulation is very useful for teaching power converters since it has proven to be a highly effective aid for linking theory and practice. With the platform presented here, students take less time to do each experiment and can, therefore, conduct more experiments in the same period of time. Before using the platform, a large number of registered students did not manage to complete the program of experiments. Student motivation is enhanced by greater involvement. In addition, practical experience has demonstrated its utility in that students assimilate the theoretical concepts better, as is shown by the answers that students give to the handout questions. As noted previously, a substantial improvement has been observed in the student pass rate (Fig. 6).

\section{SUMmARY AND FutURE WORK}

With the experimental equipment based on the reconfigurable platform as presented, students can perform complex experiments in a short period of time; they can also do the simulation on the computer and the assembly in the laboratory. The results from theory classes can be checked both on the computer and on the oscilloscope screen.

The use of the platform for the basic course experiments started in the 2001-2002 academic year. This course is offered as an optional subject to second-year industrial engineering students. During the last three years, teachers have seen a noticeable increase of student interest in this subject, as evidenced by the sharp growth of numbers registered. Two reasons account for this interest: first, students are more motivated since they are more fully involved in the conduct of the experiments, and second, students find it easier to assimilate the theory this way.

In the future, the methodology presented in this paper will be extended to advanced power electronics courses.

\section{ACKNOWLEDGMENT}

The authors would like to thank the students whose excellent work and whose comments have helped improve the experiments carried out at the Power Electronics Laboratory of the Technical University of Cartagena, Spain. The laboratory was founded by the Spanish Ministry of Education and the Regional Government of Murcia. 


\section{REFERENCES}

[1] N. Mohan, "Power electronics circuits: An overview," in Conf. Rec. 14th Annu. Conf. IEEE Industrial Electronics Society (IECON'88), Oct. 1988, pp. 522-527.

[2] D. A. Torrey, "A project-oriented power electronics laboratory," IEEE Trans. Power Electron., vol. 9, no. 3, pp. 250-255, May 1994.

[3] G. G. Karady and G. T. Heydt, "Increasing student interest and comprehension in power engineering at the graduate and undergraduate levels," IEEE Trans. Power Syst., vol. 15, no. 1, pp. 16-21, Feb. 2000.

[4] N. Mohan, W. P. Robbins, P. Imbertson, T. M. Undeland, R. C. Panaitescu, A. K. Jain, P. Jose, and T. Begalke, "Restructuring of first courses in power electronics and electric drives that integrates digital control," IEEE Trans. Power Electron., vol. 18, no. 1, pp. 429-437, Jan. 2003.

[5] V. F. Pires and J. F. A. Silva, "Teaching nonlinear modeling, simulation, and control of electronic power converters using MATLAB/ SIMULINK," IEEE Trans. Educ., vol. 45, no. 3, pp. 253-261, Aug. 2002

[6] C. D. Vournas, E. G. Potamianakis, C. Moors, and T. Van Cutsem, "An educational simulation tool for power systems control and stability," IEEE Trans. Power Syst., vol. 19, no. 1, pp. 48-55, Feb. 2004.

[7] D. W. Hart, "Circuit simulation as an aid in teaching the principles of power electronics," IEEE Tran. Educ., vol. 36, no. 1, pp. 10-16, Feb. 1993.

[8] I. Batarseh, A. Gonzalez, Z. Qu, and A. Khan, "Proposed power electronics curriculum,” in Conf. Rec. IEEE Southcon'96, Jun. 1996, pp. 251-262.

[9] SEMITEACH: Demonstrating Power Electronics (2005, Feb.). [Online]. Available: http://www.semikron.es/seminew/noticias/pdf/ n_semiteach.pdf

Jacinto M. Jiménez-Martínez was born in Cartagena, Spain, in 1972. He received the B.Sc. degree in electronics from the University of Murcia, Spain, in 1994 and the M.Sc. degree in telecommunication from the Technical University of Valencia, Spain, in 1998. He is currently working toward the Ph.D. degree in the fields of signal processing applied to biomedicine at the Medical and Industrial Electronics Group, Technical University of Cartagena, Spain.

In 1999, he joined the Electronics Technology Department at the Technical University of Cartagena, where he is working as Associate Professor in the field of power electronics. His current research interests are signal processing in biomedicine and digital control of power electronics converters.

Fulgencio Soto was born in Cartagena, Spain, in 1976. He received the B.Sc. degree in electronics from the University of Murcia, Spain, in 1997 and the M.Sc. degree in automation and industrial electronics engineering from the Technical University of Cartagena, Spain, in 2002. He is currently working toward the Ph.D. degree in the fields of power electronics applied to marine aquaculture at the Medical and Industrial Electronics Group, Technical University of Cartagena.

Since 2000, he has also been with the Electronics Technology Department at the Technical University of Cartagena, where he is currently a Lecture Assistant. His current research interests are power electronics and marine aquaculture.
Esther de Jódar received the degree in automation and industrial electronics from the Technical University of Cartagena, Spain, in 2003. She is currently working toward the Ph.D. degree in embedded systems at the Technical University of Cartagena.

In 2003, she joined the Systems and Electronic Engineering Division (DSIE), the Technical University of Cartagena. Since then, she has participated in different projects focused on renewable energies and robotics application for the industry. Her current research interests include electronics and robotics.

José A. Villarejo was born in Puerto-Lumbreras, Spain, in 1972. He received the M.Sc. degree in electrical engineering from the University of Murcia, Spain, in 1997 and the Ph.D. degree from the University of Cartagena, Spain, in 2004.

Since 1998, he has been an Assistant Professor at the Technical University of Cartagena. His research interests are switching-mode power supplies and highpower-factor rectifiers.

Joaquín Roca-Dorda (M'99) received the B.Sc. degree in electronics from the University of Murcia, Spain, in 1971, the M.S. degree in electrical and electronic engineering from the University of Murcia, Spain, in 1993, and the Ph.D. degree from the Technical University of Cartagena (UPCT), Cartagena, Spain, in 1998.

In 1973, he worked as an Assistant Engineer in E. N Bazán Military Shipyard. In 1982, he joined the University of Murcia as Lecturer. In 1998, he founded the Industrial and Medical Electronics Research Group (EIMED) at UPCT, acting as head of the group. Since 1998, he has been an Associate Professor of Electronics Technology at UPCT. His research and development objective is to design new systems and devices within the industrial electronics and biomedical engineering field (biomedical and industrial instrumentation and technical aids for the disabled and the elderly). He has coauthored more than 50 journal and conference papers, five book chapters, and three patents. He also has technical responsibility in the field of biomedical engineering applied to disabilities for the Research Institute of the UPCT. As a Member of the Domestication of Thunnus Thynnus (DOTT), steering committee of the European Union, he has been involved on the study of engineering solutions for the domestication and exploitation of blue fin tuna.

Dr. Roca-Dorda is a Member of the Spanish Society of Biomedical Engineering (SEIB), which is a society affiliated with the International Federation for Medical and Biological Engineering (IFBME). He received the "IMSERSO" Award in Disability from the Ministry of Work and Social Affairs in 1996, the Spanish Air Force Merit Cross in 1997, the Siemens Award in Intensive Medicine in 2000, and the Silver Medal of Arts-Sciences-Lettres Paris Socièté Académique in 2002. He has served as a Referee for the IEEE SENSORS JOURNAL and as a research and development evaluator for the Health and Care Spain Ministry. 